\title{
Mining Novel Effector Proteins from the Esophageal Gland Cells of Meloidogyne incognita
}

\author{
William B. Rutter, ${ }^{1}$ Tarek Hewezi, ${ }^{2}$ Sahar Abubucker, ${ }^{3}$ Tom R. Maier, ${ }^{1}$ Guozhong Huang, ${ }^{4}$ \\ Makedonka Mitreva, ${ }^{3}$ Richard S. Hussey, ${ }^{4}$ and Thomas J. Baum ${ }^{1}$ \\ ${ }^{1}$ Department of Plant Pathology and Microbiology, lowa State University, Ames 50011, U.S.A.; ${ }^{2}$ Department of Plant Sciences, \\ University of Tennessee, Knoxville 37996-4561, U.S.A.; ${ }^{3}$ The Genome Center, Department of Genetics, Washington University \\ School of Medicine, St. Louis 63108, U.S.A.; ' ${ }^{2}$ epartment of Plant Pathology, University of Georgia, Athens 30602-7274, \\ U.S.A.
}

Submitted 13 March 2014. Accepted 23 May 2014.

\begin{abstract}
Meloidogyne incognita is one of the most economically damaging plant pathogens in agriculture and horticulture. Identifying and characterizing the effector proteins which $M$. incognita secretes into its host plants during infection is an important step toward finding new ways to manage this pest. In this study, we have identified the cDNAs for 18 putative effectors (i.e., proteins that have the potential to facilitate $M$. incognita parasitism of host plants). These putative effectors are secretory proteins that do not contain transmembrane domains and whose genes are specifically expressed in the secretory gland cells of the nematode, indicating that they are likely secreted from the nematode through its stylet. We have determined that, in the plant cells, these putative effectors are likely to localize to the cytoplasm. Furthermore, the transcripts of many of these novel effectors are specifically upregulated during different stages of the nematode's life cycle, indicating that they function at specific stages during $M$. incognita parasitism. The predicted proteins showed little to no homology to known proteins from free-living nematode species, suggesting that they evolved recently to support the parasitic lifestyle. On the other hand, several of the effectors are part of gene families within the $M$. incognita genome as well as that of $M$. hapla, which points to an important role that these putative effectors are playing in both parasites. With the discovery of these putative effectors, we have increased our knowledge of the effector repertoire utilized by rootknot nematodes to infect, feed on, and reproduce on their host plants. Future studies investigating the roles that these proteins play in planta will help mitigate the effects of this damaging pest.
\end{abstract}

The southern root-knot nematode (Meloidogyne incognita) is one of the most economically devastating plant pathogens in the world and is able to infect nearly every cultivated crop species (Koenning et al. 1999; Sasser and Freckman 1986). The paucity of effective control strategies for this widely problematic pest makes it crucial to understand the mechanisms re-

Corresponding author: T. J. Baum; Telephone: +1.515.294.2398; Fax: +1.515.294.9420; E-mail: tbaum@iastate.edu

* The $\boldsymbol{e}$-Xtra logo stands for "electronic extra" and indicates that one supplementary figure and one supplementary table are published online.

(C) 2014 The American Phytopathological Society sponsible for its ability to infect plants so that novel control strategies can be developed.

$M$. incognita engages in a complex interaction with its host plants. In order to survive, the obligate parasite must penetrate a host plant root, overcome host defenses, develop elaborate feeding cells within the host (referred to as giant cells), and maintain these giant cells as it grows and reproduces. To perform these vital steps, the nematode secretes effector proteins that interact with and manipulate host plant factors. The functions that these effectors perform in planta are critical for the nematode to infect its host plants (Abad and Williamson 2010; Hewezi and Baum 2013; Mitchum et al. 2013).

Previously characterized effector proteins from $M$. incognita have been shown to have diverse functions when secreted into the host plants. One such effector protein, 16D10, has been shown to interact with two plant SCARECROW-like transcription factors and, in doing so, it increases the susceptibility of the host to $M$. incognita infection (Huang et al. 2006). M. incognita also secretes a calreticulin effector protein, which accumulates in the plant apoplast (Jaubert et al. 2005), and has recently been shown to suppress basal immunity within its plant host to facilitate parasitism (Jaouannet et al. 2013). Other effectors that are secreted from both root-knot and cyst nematodes (Heterodera and Globodera spp.) show homology to chorismate mutases and have been shown to alter plant development when expressed in planta (Bekal et al. 2003; Doyle and Lambert 2003). Yet another effector gene, $M j-N U L G$, was recently isolated from the closely related species $M$. javanica and was shown to be specifically upregulated during feedingsite development and to localize to the nucleus of the giant cells, where it is assumed to play a role in facilitating nematode parasitism (Lin et al. 2012). Similarly, the secreted M. incognita effector, Mi-EFF1, was shown to localize to the plant nucleus, where it has the potential to manipulate host transcriptional machinery (Jaouannet et al. 2013). These recent characterization studies highlight the important roles effectors play in specific plant subcellular compartments and at specific times during the parasite's life cycle.

An impressive number of $M$. incognita effectors have been identified (Bellafiore et al. 2008; Danchin et al. 2013; Huang et al. 2003) but a complete panel of effectors remains elusive, even with the availability of the $M$. incognita genome (Abad et al. 2008). Identification of effectors frequently relies on the ascertainment of gland-cell-specific expression of effector genes as well as the documentation of an N-terminal signal peptide for protein secretion and the absence of transmembrane domains, which otherwise would suggest a retention inside the 
nematode gland cells. Despite extensive efforts in the last few years, the majority of Meloidogyne effector proteins remain undiscovered and uncharacterized. This stresses the need for more complete knowledge of the $M$. incognita effector repertoire and a better understanding of how individual effectors function within host tissues.

Past efforts to identify effectors have utilized whole-nematode expressed sequence tags as well as proteomics approaches and have found a number of candidates (Bellafiore et al. 2008; Roze et al. 2008). The most successful approach, however, has incorporated the sequencing of mRNA isolated specifically from the esophageal region of the nematode, which contains three gland cells (one dorsal and two subventral) that secrete nematode effectors (Huang et al. 2003). This type of tissue-specific transcriptome analysis has been successfully implemented in both animals and plants to identify low-abundance transcripts that would have been missed when sequencing transcriptomes of the entire organism (Brandt 2005; Chemello et al. 2011). This approach, in conjunction with Sanger sequencing methods, has identified 37 putative $M$. incognita effector proteins to date (Huang et al. 2003). Though this is an extensive list, the fact that there are currently more than twice the number of known effector proteins from cyst nematodes leads us to believe that there should be a comparable number of effectors in $M$. incognita.

In this current effort to search for previously undiscovered effectors from $M$. incognita, gland-cell-specific mRNA was isolated and sequenced using Roche 454 technology, allowing for significantly greater read coverage than previous approaches. The resulting transcript data were analyzed using a combination of in silico and molecular approaches to identify $18 \mathrm{M}$. incognita genes encoding putative effector proteins that are expressed specifically in the esophageal gland cells.

The secreted proteins encoded by these $M$. incognita genes have no annotated function and no orthologs in free-living organisms, yet many are members of gene families and are conserved within the genome of $M$. hapla, suggesting a conserved and specific function within the two parasites. Quantitative realtime reverse-transcriptase polymerase chain reaction (qRT-PCR) allowed us to identify several unique expression profiles for these genes during the sedentary parasitic stages of $M$. incognita infection. Furthermore, subcellular localization revealed that the majority of these putative effectors localize to the cytoplasm in planta. Together, our data suggest that these $18 \mathrm{M}$. incognita genes encode secreted proteins with specific roles at different stages of parasitism, and that the majority likely functions within the cytoplasm of the giant cells. The discovery of these new putative effectors has expanded the known $M$. incognita secretome and laid the groundwork for a greater understanding of the molecular basis of nematode parasitism.

\section{RESULTS}

\section{Sequencing and assembly.}

The cytoplasm of esophageal gland cells was microaspirated from $50 \mathrm{M}$. incognita nematodes at different parasitic stages to isolate total RNA. The mRNA was then purified and used to generate cDNA (as described in Materials and Methods). The synthesized cDNAs were used to prepare one nebulized and one non-nebulized pool of cDNA. Each cDNA pool was sequenced using Roche 454 technology, which produced a combined total of 1.7 million reads with an average length of 281 bp. Reads with insufficient complexity to facilitate assembly were removed (SeqClean software), leaving 623,000 clean reads. These high-quality reads were assembled using Newbler V2.5 software producing 17,741 isotigs (unique transcripts), which were predicted to be contained within 14,443 isogroups (unique genes), alongside 72,397 singletons. To identify the full-length transcripts, we compared the 17,741 isotigs with the 20,359 proteins predicted from the M. incognita genome (Abad et al. 2008) using BLASTx, with a minimum cut-off of $90 \%$ identity over $75 \%$ of the isotig length. We found that 5,700 gland isotigs (4,548 isogroups) had strong sequence homology to 3,758 known $M$. incognita proteins from the $M$. incognita genome (Fig. 1A). These full-length proteins were subjected to several criteria to identify novel effector candidates, as detailed below.

\section{In silico filtering of effector candidates.}

Most known nematode effectors have evolved to become specific to the parasitic lifestyle and do not have obvious

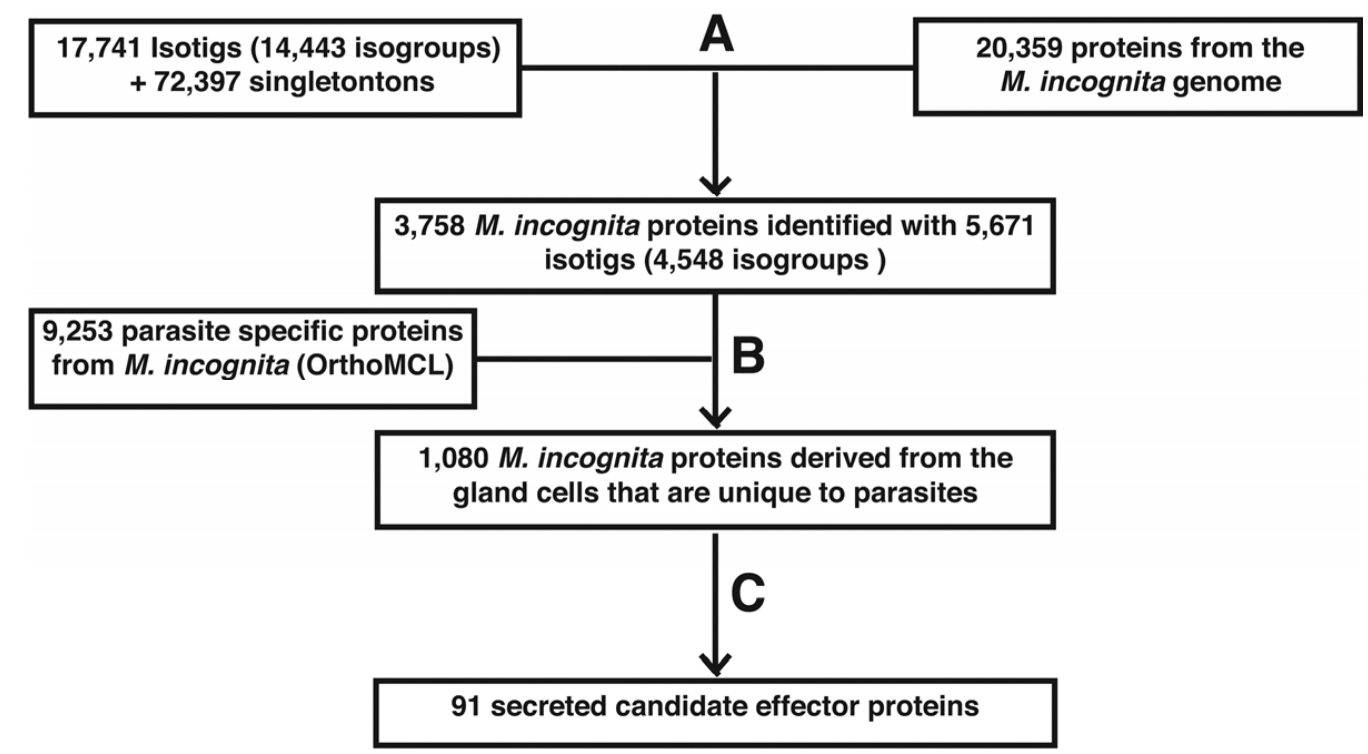

Fig. 1. Diagram of in silico filtering methods used to identify effector candidates. A, Isotigs assembled from the gland-cell-derived sequences were compared with the known protein coding sequences from the Meloidogyne incognita genome using a nucleotide BLAST (minimum cut off of $90 \%$ identity over $70 \%$ of an isotig's length). B, M. incognita proteins represented in the gland-derived sequences were compared with known parasite-specific $M$. incognita proteins (previously predicted using OrthoMCL (Abubucker et al. 2011). C, Identified $M$. incognita proteins were analyzed for the presence of an N-terminal secretion signal and the absence of transmembrane domains (Phobius). 
orthologs in nonparasitic species. This has been demonstrated by the lack of sequence homology between the previously identified effector proteins from cyst and root-knot nematode parasites and free-living species (Huang et al. 2003). Therefore, we used this criterion to filter our dataset of 3,758 proteins identified from the $M$. incognita gland region. To determine which of the candidate proteins have orthologous sequences that are specific to parasitic species and absent in freeliving species, we utilized a dataset previously generated using OrthoMCL (Abubucker et al. 2011). This dataset contained the known proteomes from seven helminth parasites (M. incognita, M. hapla, Trichinella spiralis, Brugia malayi, Schistosoma japonicum, and S. mansoni), two host plants (Glycine max and Arabidopsis thaliana), as well as proteins from nine free-living species (Pristionchus pacificus, Saccharomyces cerevisiae, Drosophila melanogaster, Mus musculus, Homo sapiens, and five Caenorhabditis spp.) (Abubucker et al. 2011; Chen et al. 2006). The Ortho MCL algorithm clustered these 18 proteomes into 38,776 groups of orthologous and paralogous proteins. Of all the groups, 2,419 contained orthologous proteins only from parasites or host plant species, and lacked proteins from the free-living $S$. cerevisiae, Drosophila, and Caenorhabditis spp. We further scrutinized the 4,073 proteins from $M$. incognita that were contained in these 2,419 parasitespecific groups. These 4,073 proteins, in addition to 5,180 M. incognita proteins that were not clustered with any other proteins, were combined $(9,253$ proteins) and compared with our 3,758 gland-enriched candidate proteins. This comparison resulted in the identification of 1,080 gland-derived proteins that were not found in protein clusters with free-living species and, therefore, likely have evolved specifically for parasitic life-styles (Fig. 1B).

One of the hallmark characteristics of nematode effector proteins is the presence of a secretion signal peptide on their $\mathrm{N}$ terminus that targets the mature protein to the secretory pathway, as well as the absence of internal transmembrane domains that would retain the protein in membranes of nematode cells. Therefore, we analyzed the 1,080 parasite-specific gland-derived proteins for the presence of secretion signals and the absence of internal transmembrane domains (Kall et al. 2004). This selection procedure resulted in the identification of 91 candidate effector genes (Fig. 1C; Supplementary Table S1). Effector candidates were then subjected to RNA in situ hybridization to determine whether they are expressed specifically in the esophageal gland cells.

Because esophageal gland cells are directly connected through the esophagus to the nematode stylet, secretory proteins that are exclusively expressed in and secreted from these gland cells are very likely to have biological functions in the nematodeplant interactions. To determine the gland-specific expression patterns of the 91 candidate effector genes, we generated specific antisense digoxigenin (DIG)-labeled probes for each candidate and hybridized these to fixed $M$. incognita nematodes at different parasitic life stages. Out of the 91 candidates tested, probes for 14 individual candidate effectors were found to specifically hybridize to mRNA accumulating within the subventral (10 probes) or dorsal ( 3 probes) gland cells of $M$. incognita (Fig. 2; Table 1). Interestingly, another candidate protein (Minc00801) showed strong and specific expression in the rectal glands of fourth-stage juvenile (J4) female M. incognita

Table 1. Summary of the18 putative effector genes identified in this study ${ }^{\mathrm{a}}$

\begin{tabular}{|c|c|c|c|c|c|}
\hline $\begin{array}{l}\text { Meloidogyne incognita } \\
\text { CDS (bp) }{ }^{\mathbf{b}}\end{array}$ & $\begin{array}{l}\text { M. incognita paralogs } \\
\text { (\% ID, bit score) }\end{array}$ & $\begin{array}{l}\text { M. hapla orthologs } \\
(\% \text { ID, bit score })^{\mathrm{c}}\end{array}$ & $\begin{array}{l}\text { NCBI homology } \\
(\% \text { ID, bit score })^{d}\end{array}$ & $\begin{array}{l}\text { Predicted } \\
\text { domains }^{\mathrm{e}}\end{array}$ & $\begin{array}{c}\text { Gland } \\
\text { localization }\end{array}$ \\
\hline *Minc13292 (1,605) & Minc03325 $(80 \%, 721)$ & N/A & N/A & N/A & SvG \\
\hline *Minc18861 (453) & Minc11817 $(100 \%, 313)$ & $\begin{array}{l}\text { Contig1084.frz3.gene } 4 \\
(68 \%, 105)\end{array}$ & N/A & N/A & DG \\
\hline$*$ Minc08073 (2,133) & Minc10418 $(98 \%, 1389)$ & N/A & N/A & N/A & SvG \\
\hline *Minc00801 $(1,086)$ & N/A & $\begin{array}{l}\text { Contig 125.frz3.gene5 } \\
(79 \%, 62.8)\end{array}$ & N/A & NLS & RG \\
\hline *Minc02097 (1,599) & Minc01595 $(92 \%, 933)$ & N/A & $\begin{array}{l}\text { Putative esophageal gland cell protein } 25 \\
{[\text { M. incognita }](97 \%, 1060)}\end{array}$ & N/A & DG \\
\hline *Minc18033 (1,314) & N/A & $\begin{array}{l}\text { Contig518.frz3.gene7 } \\
(64 \%, 412)\end{array}$ & $\begin{array}{l}\text { Putative esophageal gland cell protein } 17 \\
{[\text { M. incognita }](99 \%, 884)}\end{array}$ & N/A & SvG \\
\hline *Minc01696 (1,731) & N/A & $\begin{array}{l}\text { Contig83.frz3.gene } 1 \text { and } \\
\text { gene } 2(95 \%, 32)\end{array}$ & $\begin{array}{l}\text { Dual specificity protein kinase TTK } \\
\text { [Rattus norvegicus }](30 \%, 123)\end{array}$ & PK & SvG \\
\hline *Minc00344 $(1,158)$ & Minc04584 $(90 \%, 312)$ & $\begin{array}{l}\text { Contig252.frz3.gene } 17 \\
(52 \%, 167)\end{array}$ & $\begin{array}{l}\text { Putative avirulence protein MAP-1 } \\
{[\text { M. incognita }](47 \%, 185)}\end{array}$ & NLS & $\mathrm{SvG}$ \\
\hline *Minc00469 (198) & N/A & N/A & N/A & N/A & SvG \\
\hline *Minc15401 (951) & Minc18636 $(94 \%, 249)$ & $\begin{array}{l}\text { Contig1554.frz3.gene } 5 \\
(71 \%, 155)\end{array}$ & N/A & N/A & SvG \\
\hline$*$ Minc10418 $(2,130)$ & Minc08073 $(98 \%, 1385)$ & N/A & N/A & NLS & SvG \\
\hline *Minc12639 (303) & N/A & $\begin{array}{l}\text { Contig 1246.frz3.gene } 18 \\
(94 \%, 75 b)\end{array}$ & N/A & N/A & DG \\
\hline *Minc03328 $(1,449)$ & N/A & N/A & $\begin{array}{l}\text { Unnamed protein product [Trypanosoma } \\
\text { congolense IL3000] }(25 \%, 38.1)\end{array}$ & N/A & SvG \\
\hline *Minc04584 (630) & Minc00344 $(82 \%, 327)$ & $\begin{array}{l}\text { Contig252.frz3.gene } 17 \\
(66 \%, 142)\end{array}$ & $\begin{array}{l}\text { Putative avirulence protein MAP-1 }[M . \\
\text { incognita }(40 \%, 135)\end{array}$ & NLS & SvG \\
\hline Minc03325 (1,593) & Minc13292 $(79 \%, 721)$ & N/A & N/A & N/A & SvG \\
\hline Minc11817 (453) & Minc18861 $(100 \%, 313)$ & $\begin{array}{l}\text { Contig1084.frz3.gene } 4 \\
(68 \%, 105)\end{array}$ & N/A & N/A & DG \\
\hline Minc01595 $(1,653)$ & Minc02097 $(87 \%, 923)$ & N/A & $\begin{array}{l}\text { Putative esophageal gland cell protein } 25 \\
{[\text { M. incognita }](87 \%, 921)}\end{array}$ & N/A & DG \\
\hline Minc18636 (939) & Minc15401 $(87 \%, 385)$ & $\begin{array}{l}\text { Contig1554.frz3.gene5 } \\
(55 \%, 151)\end{array}$ & 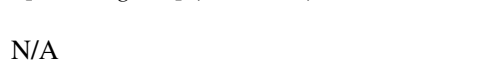 & N/A & $\mathrm{SvG}$ \\
\hline
\end{tabular}

${ }^{a}$ Asterisks $(*)$ indicate the original 14 effectors identified from the list of 91 candidates and N/A = not applicable.

${ }^{\mathrm{b}}$ Amino acid similarity to paralogous genes in the M. incognita genome (BLASTp percent identity and bit score).

${ }^{\mathrm{c}}$ Amino acid similarity with orthologous proteins containing signal peptides in the M. hapla genome (BLASTp percent identity and bit score).

${ }^{\mathrm{d}}$ Highest homolog in the National Center for Biotechnology Information (NCBI)-nr database (BLASTp minimum cutoff $>35$ bits).

${ }^{\mathrm{e}}$ Protein domains predicted using InterPro Scan software, and nuclear localization signals (NLS) predicted using PSORT II. PK = protein kinase.

${ }^{\mathrm{f}}$ Gland-specific expression found in the dorsal gland (DG), the subventral glands (SvG), or the rectal glands (RG) using in situ hybridization. 
(Fig. 2Q). Because the rectal glands are known to form the egg mass matrix (Maggenti and Allen 1960), this candidate is potentially secreted into plant tissues and worthy of further analysis, although its presence in the gland-enriched RNA sample was unexpected. In total, 14 proteins were identified as likely to have effector roles in $M$. incognita parasitism of host plants
(Table 1). The remaining 77 candidate genes displayed either non-gland cell hybridization signals or no visible staining signals at all.

Sequence analysis of these 14 candidate effector genes revealed that two of these proteins, Minc10418 and Minc08073, had $98 \%$ amino acid identity, indicating that they are likely
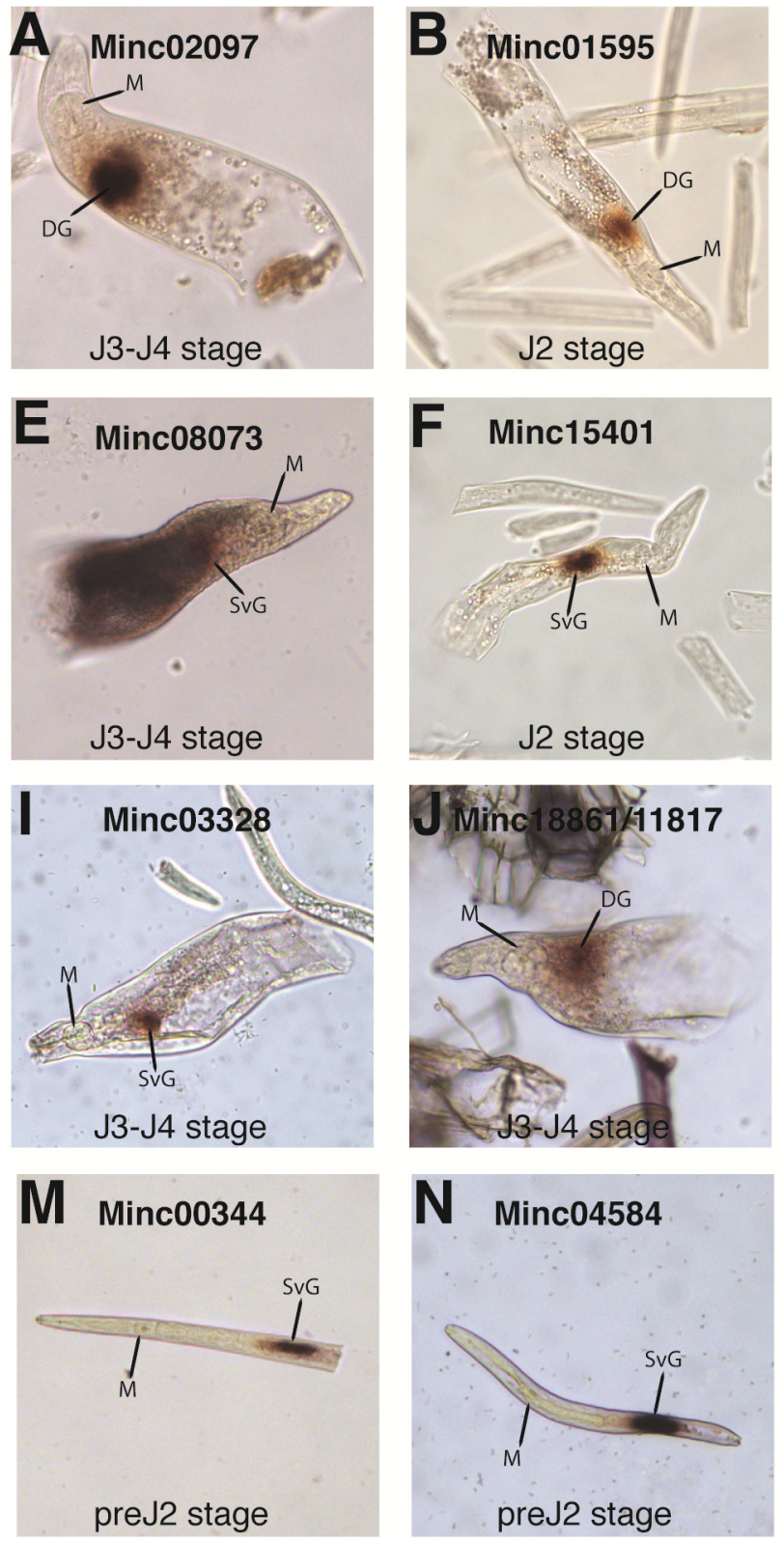
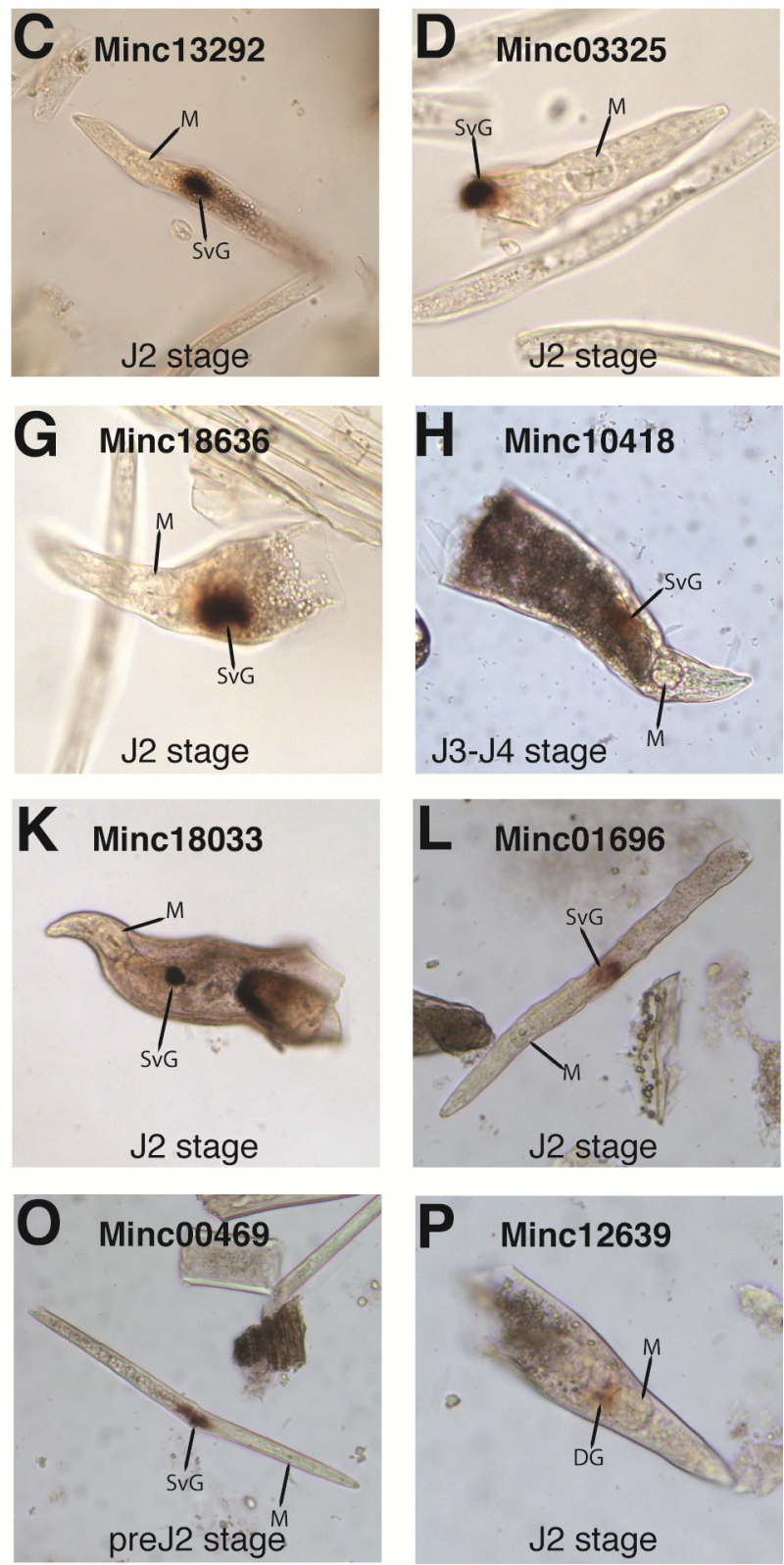

\section{Q Minc00801}

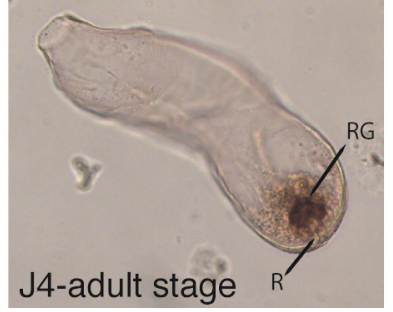

Fig. 2. Detection of digoxigenin-labeled probes hybridized to transcripts expressed within the secretory gland cells of Meloidogyne incognita. A to $\mathbf{P}$, In total, 16 probes detected transcripts from 17 genes expressed specifically within the dorsal (DG) or subventral (SvG) esophageal gland cells. M, With each probe, 10 to 30 nematodes were hybridized, and specific gland expression was determined by the shape, size, and proximity of the stained region relative to the metacarpus. Q, One probe specific for Minc00801 produced specific staining in the rectal glands (RG) attached to the rectum (R) of stage-four juvenile (J4) female nematodes. 
paralogous members of a gene family within $M$. incognita. Two other proteins, Minc00344 and Minc04584, belong to the previously identified MAP-1 gene family, whose members are thought to play roles at the early stages of interaction between M. incognita and its host plants (Castagnone-Sereno et al. 2009; Semblat et al. 2001). Two additional proteins, Minc02097 and Minc18033, showed near-perfect identity with the putative esophageal gland-cell effector proteins 35A02 and 19F07, respectively (Huang et al. 2003). Finally, eight of the 14 candidate effectors showed no significant sequence similarity to any proteins in the databases and, therefore, were designated novel effectors.

The 14 novel candidate effectors were analyzed for the presence of known motifs and domains using InterProScan (Quevillon et al. 2005). Only one putative effector (Minc01696) was predicted to contain a known functional protein domain. This protein contained a region of 337 amino acids with strong sequence similarity $(9 \mathrm{e}-27)$ to TTK dual-specificity protein kinases from multiple metazoan species. This region was located 17 residues from the predicted signal peptide cleavage site and was predicted to contain a complete protein kinase catalytic domain (PS50011 InterProScan, score = 29.997). This putative effector also contains an additional 210 residues on its $\mathrm{C}$ terminus, with no sequence similarity to any known protein (Table 1).

\section{Certain putative effectors have paralogs}

\section{in $M$. incognita and orthologs in related parasites.}

Pathogen effectors that play essential roles in parasitism are often represented by multiple paralogous copies within their respective genomes (Haas et al. 2009; Raffaele et al. 2010). These paralogs are thought to have redundant or specific functions and may promote plasticity in effector function. To determine whether the newly mined effectors have paralogs, the protein sequences of these 14 putative effectors were used as queries in blast searches against the known proteins from the $M$. incognita genome. Interestingly, four of these proteins showed significant blast hits (BLASTp > 150 bits, 50\% identity [ID]) to other proteins with predicted signal peptides, making these related proteins good effector candidates as well. To determine whether these new paralogs had been detected in our in situ hybridization, the probes used to identify the original effector genes were compared with the coding sequences of the newly identified paralog candidates. One paralogous pair, Minc18861 and Minc11817, showed perfect coding sequence homology, indicating that the original probe used was likely cross-hybridizing with both transcripts within the gland cells. The other three pairs of paralogs showed significant polymorphisms in the region of the original in situ hybridized probes. To assure that all of the secreted paralogs were indeed expressed specifically in the secretory gland cells, new probes were designed to specifically hybridize to each paralog. When these probes were used in in situ hybridization on mixed-stage $M$. incognita tissue, all three paralogous genes were shown to be specifically expressed in the same esophageal gland cells as their originally discovered paralog (Table 1; Fig. 2). This raised the total number of newly discovered putative effectors to 18 genes within $M$. incognita.

Genome-wide comparison of protein sequences between $M$. incognita and the closely related root-knot nematode $M$. hapla revealed that both genomes contain orthologous sequences (Bird et al. 2009). To determine whether the newly identified putative effectors have orthologs in M. hapla, each was blasted against the predicted proteins from the $M$. hapla genome (Opperman et al. 2008). Importantly, 10 of the $M$. incognita effectors have homologs (BLASTp > 35 bits, $50 \%$ ID) in $M$. hapla, which were also predicted to contain secretion signal peptides. These proteins are likely part of orthologous effector
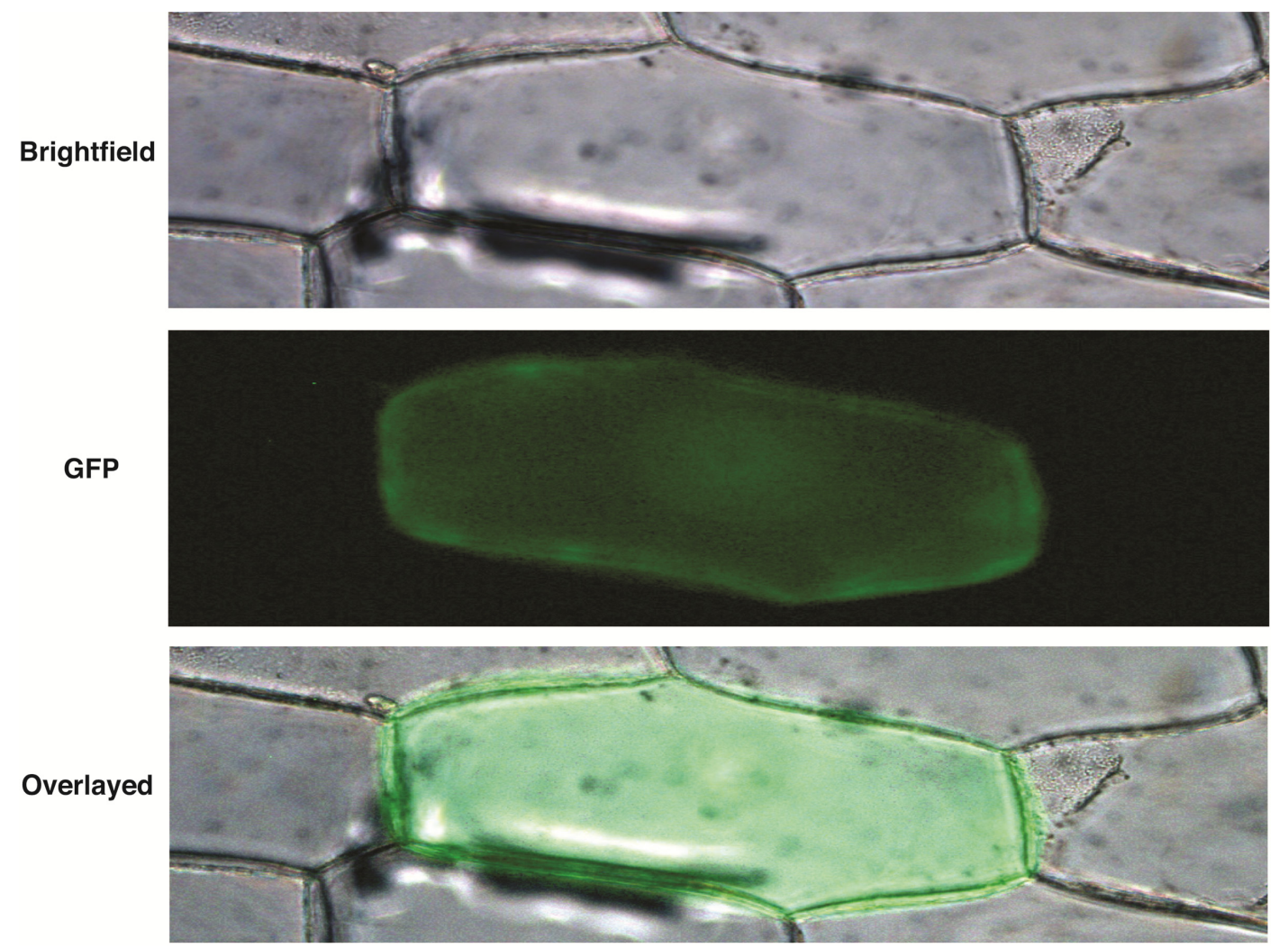

Fig. 3. Subcellular localization of effector-yellow fluorescent protein (YFP) fusion proteins in onion epidermal cells. N-terminal YFP fusion constructs were made for 11 of the putative effector proteins cloned from Meloidogyne incognita. All effector protein candidates, including Minc00469 (above), produced a cytoplasmic YFP signal when expressed into onion epidermal cells. 
families that carry out similar functional roles in both $M$. hapla and $M$. incognita parasitism.

Putative effectors localize to the cytoplasm in planta.

The in planta subcellular localization of nematode effectors provides clues to their site of action and the identity of potential host targets. To determine the cellular compartments where the newly identified nematode effectors would localize, the full-length coding sequences (minus signal peptides) of 11 effectors were fused to yellow fluorescent protein (YFP) reporter gene under the control of the Cauliflower mosaic virus (CaMV) 35S promoter. These constructs were delivered into onion epidermal cells by biolistic bombardment. All of the fusion proteins showed cytoplasmic localization in the plant cells (Fig. 3; Supplementary Fig. S1). These data are consistent with the cytoplasmic localization prediction using Psort II software (Yu et al. 2010).
Putative effectors are differentially expressed at different stages of $M$. incognita parasitism.

Nematode effector genes are known to be developmentally regulated, with increasing mRNA abundance during the parasitic stages. The developmental expression profiles of 12 of the newly identified parasitism genes were successfully quantified using qRT-PCR in eggs, preparasitic second-stage juveniles (J2s), and parasitic $M$. incognita stages at 3, 7, 14, and 21 days postinfection (dpi) (Fig. 4). All 12 putative effector genes displayed the lowest detectable expression levels in eggs. In contrast, the expression patterns during other developmental stages varied widely. Two effector candidates (Minc01696 and Minc10418/Minc08073) showed significant upregulation at 3 dpi (Fig. 4A and B), while four additional transcripts (Minc2097, Minc00344, Minc13292, and Minc03328) showed upregulation during the first three parasitic time points $(3,7$, and $14 \mathrm{dpi}$ ), followed by a distinct downregulation at $21 \mathrm{dpi}$.

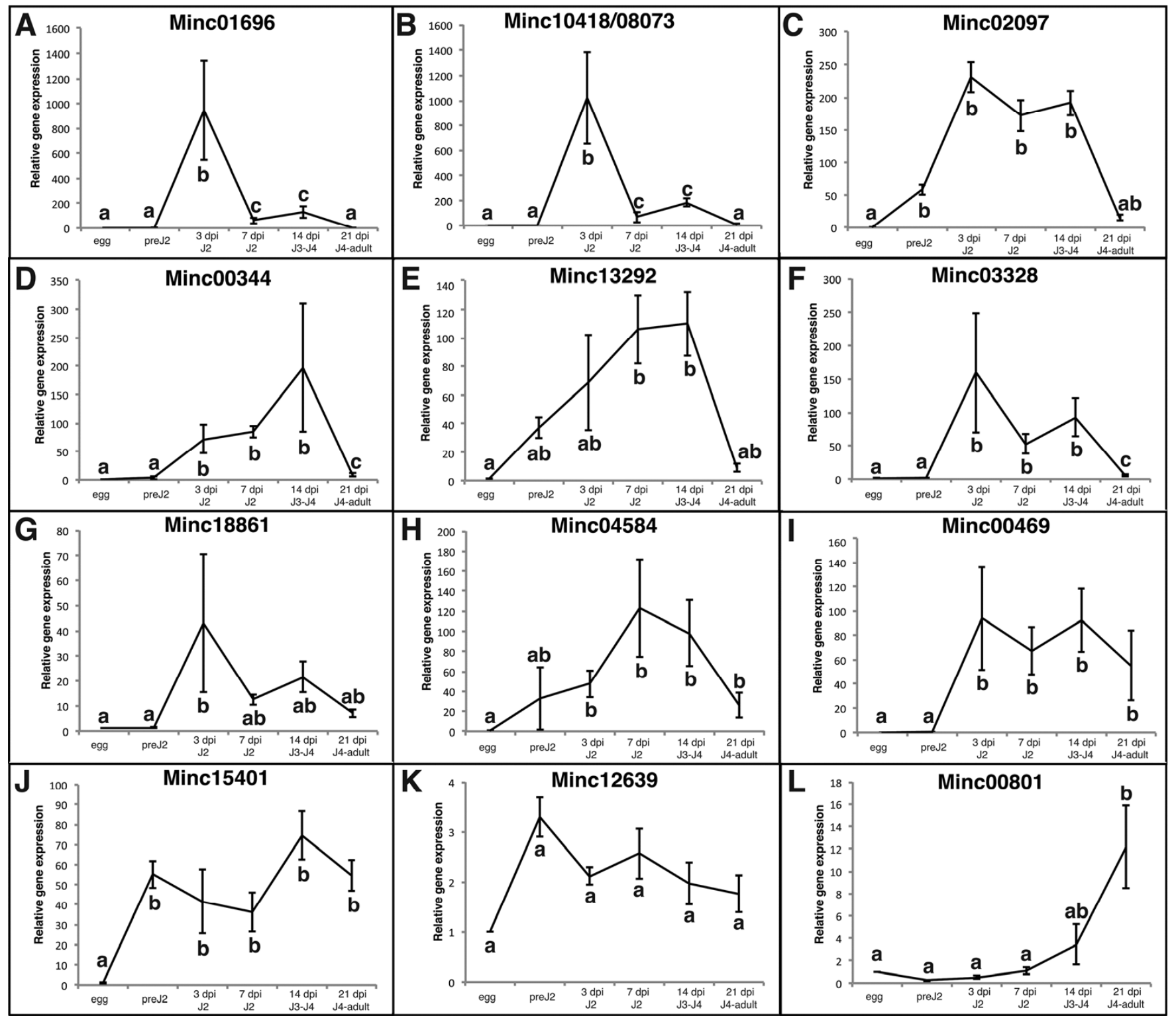

Fig. 4. Quantitative real-time reverse-transcriptase polymerase chain reaction expression analysis of putative effector genes over the life-cycle of Meloidogyne incognita. A and $\mathbf{B}$, Two putative effector genes that show a significant increase in expression at 3 days postinfection (dpi). $\mathbf{C}$ through $\mathbf{F}$, Four putative effector genes that show relatively high expression during the parasitic stages of $M$. incognita $(3,7$, and 14 dpi) and show a significant decrease during the adult stage at 21 dpi. $\mathbf{G}$ through $\mathbf{K}$, Five putative effector genes that show a relatively constant expression pattern across all four infection time points ( 3 to 21 dpi). L, Minc00801, the rectal gland-specific transcript, shows a significant increase in expression during the adult stage of $M$. incognita at 21 dpi. Relative gene expression values represent changes of the expression levels of various parasitic stages relative to eggs. Data are averages of four biologically independent samples \pm standard error. Statistically significant differences between mean values $(P=0.05)$ are indicated where letters $(\mathrm{a}, \mathrm{b}$, and $\mathrm{c})$ differ. 
Uniquely, Minc00801 has relatively low expression during the first five time points followed by obvious upregulation at 21 dpi (Fig. 4L). These distinct expression patterns suggest that these effectors may have stage-specific functions during nematode parasitism of host plants.

\section{DISCUSSION}

Previous studies have successfully identified putative effector proteins that are specifically expressed in the esophageal gland cells of $M$. incognita and other plant-parasitic nematodes (Gao et al. 2001; Huang et al. 2003). However, the complexity of the plant-nematode interaction indicates that the $M$. incognita effector repertoire is more extensive than previously described. To expand the known effector repertoire of $M$. incognita, we isolated mRNA from the esophageal gland cells and applied Roche 454 sequencing technology to obtain high read coverage. We also took advantage of the availability of the whole-genome sequence of M. incognita (Abad et al. 2008) to identify full-length coding sequences of our gland-derived reads. This approach facilitated the bioinformatic identification of candidate effectors based on homology models and the presence of an $\mathrm{N}$-terminal signal peptide sequence. Combining this bioinformatic approach with an in situ hybridization screen resulted in the identification of 18 novel putative effector genes, whose expression was specifically localized to the esophageal gland cells of $M$. incognita.

As in previous studies (Danchin et al. 2013; Huang et al. 2003), the majority of these proteins are unique to $M$. incognita, showing no homology to proteins in the nonredundant database and containing no detectable functional domains. Only a few of the effector proteins secreted from any parasite are widely conserved and, more often than not, they are exclusively produced by one pathogen or a group of closely related pathogens. Most likely, this observation is due to the fact that effectors from both fungal and oomycete pathogens have been shown to be under increased diversifying selection pressure to avoid the host immune system (Haas et al. 2009; Schirawski et al. 2010). As a result of this increased selection pressure, effector proteins quickly evolve to become specific to certain parasites and tend to show little homology with other proteins. This unique nature of effector proteins often makes it difficult to predict their functions, and stresses the need for functional characterizations of each individual effector.

One positive candidate, Minc01696, was predicted to contain a complete kinase domain (InterPro scan and CDD). This predicted kinase domain has high homology to the unique dualspecificity kinase domains of the monopolar spindle (MPS1) family of protein kinases. MPS1 kinases are conserved in vertebrates, invertebrates, fungi, and plants (de Oliveira 2012; Liu and Winey 2012). Members of this family have been shown to play important roles in modulating the cell cycle by acting as part of the spindle assembly checkpoint machinery (Liu and Winey 2012). In fact, it has been shown recently that increased levels of MPS1 in human cancer cells mediated the formation of aneuploid nuclei (Daniel et al. 2011). In light of the fact that giant cells induced by Meloidogyne spp. are also characterized by multiple aneuploid nuclei (Huang 1985; Jones and Payne 1978), we speculate that Minc01696 could function analogously to the MPS1 kinases in plants, perhaps facilitating aneuploidy during the formation of the giant cells. This hypothesis is further supported by our qRT-PCR data showing that Minc01696 exhibits specific and significant upregulation at 3 dpi (Fig. 4A), which coincides with the initial formation of giant cells. More in-depth characterization will be needed to determine whether or not Minc01696 functions as an MPS1 kinase in planta.
Two other putative effectors, Minc04584 and Minc00344, previously have been shown to be members of the MAP gene family (Castagnone-Sereno et al. 2009). Members of this gene family are thought to play roles in the early interaction between root-knot nematodes and their host plants. More specifically, the first MAP family member (MAP-1) was isolated as a candidate avirulence protein and was shown to be secreted from the amphids of $M$. incognita as the nematode migrates through the host root (Semblat et al. 2001). MAP-1 was later found to be part of a seven-member gene family within the $M$. incognita genome (Castagnone-Sereno et al. 2009). Though the exact function of this gene family has yet to be described, the MAP-1 transcript has recently been isolated from 12 different Meloidogyne spp. (Tomalova et al. 2012), indicating that it has an indispensable function for parasitism across Meloidogyne spp. In contrast to the amphid localization previously described for the MAP-1 protein (Semblat et al. 2001; Vieira et al. 2011), we found that both Minc04584 and Minc00344 are strongly expressed in the subventral gland cells of $M$. incognita (Fig. 2M and N). The fact that Minc04584 and Minc00344 are more distantly related to MAP-1 than the rest of the family members could explain the different cell specificity of MAP protein family members. The MAP family proteins seem to be secreted from both the amphids and stylet, and this establishes these family members as important factors in the parasitism of host plants.

Although the majority of effector proteins tend to be unique to specific parasites and not widely conserved in free-living organisms, there are certain families of effectors that are wellconserved within related groups of parasites. The large effector repertoire of the plant pathogen Ralstonia solanacearum contains three effector gene families that are broadly conserved across different strains of the bacteria (Poueymiro and Genin 2009). These conserved gene families are thought to play basal roles in facilitating infection in a wide variety of hosts. Previous analysis of cyst and root-knot nematode effector repertoires has revealed that many effectors are also organized into gene families (Abad et al. 2008; Gao et al. 2001; Huang et al. 2003). In the current study, we found that 10 of the 18 putative effector genes are organized in gene families within the $M$. incognita genome. We have shown that these gene families can be used to identify other effector candidates. By searching the $M$. incognita genome, we were able to identify paralogs of our initial in situ positive candidates. These paralogs turned out to be positive effector candidates that weren't identified in our original screen. Indeed, every identified paralog with a signal peptide was also shown to be expressed specifically in the esophageal gland cells. Using the putative effector genes from $M$. incognita, we were also able to identify seven orthologous proteins in the $M$. hapla genome as effector candidates. These findings validate the use of this approach in future studies to identify other effector candidates in $M$. incognita as well as other closely related root-knot nematode species. Conservation of these orthologous gene family members in multiple rootknot nematode species indicates that they may have fundamental roles in facilitating nematode parasitism. It would be interesting to study whether these effector proteins also have conserved orthologs in other parasites. A more comprehensive analysis of all root-knot nematode species could identify the most conserved and, presumably, the most indispensable effector families within the Meloidogyne genus.

Recent experimental data have provided evidence of extracellular, cytoplasmic, and nuclear targeting of root-knot nematode effectors, suggesting diverse functional activities in the infected host cells (Elling et al. 2007; Hewezi et al. 2008; Tytgat et al. 2004). Knowing where effectors localize in planta could help guide future analysis of their function. Previous studies 
have used bioinformatic predictions to localize root-knot nematode effectors to specific host subcellular compartments (Bellafiore et al. 2008; Huang et al. 2003). Here, we studied the subcellular localization of the newly identified effectors (Fig. 3). All candidate effectors tested displayed a cytoplasmic localization, despite the fact that some of these effectors contain predicted nuclear localization signals. It is possible that these effectors could be redirected toward specific subcellular compartments via host interacting factors. This type of effector interaction has been observed for certain cyst nematode effector proteins (Hewezi and Baum 2013).

Nematode effector genes are often differentially regulated over the course of the parasite's life cycle. An effector gene that is specifically expressed during a certain stage of infection is likely to play a specific role during that stage of infection. Quantifying the expression profiles of all identified candidate effector genes over the course of $M$. incognita infection of tomato plants revealed distinct stage-specific expression patterns. More specifically, two effector candidates (Minc01696 and Minc10418/Minc08073) showed significant upregulation at 3 dpi (Fig. 4A and B). This early time point coincides with the initiation of the giant cells, suggesting that these genes may have functional roles during the establishment of the feeding site. Four additional transcripts (Minc2097, Minc00344, Minc13292, and Minc03328) showed upregulation during the first three parasitic time points $(3,7$, and $14 \mathrm{dpi})$, followed by a distinct downregulation at $21 \mathrm{dpi}$ (when adult females begin to reproduce) (Fig. 4C to F). This pattern of expression is consistent with a potential involvement of these putative effectors in early and late events of parasitism but not for nematode reproduction. Interestingly, the opposite trend was observed for the candidate effector Minc00801, which exhibits a relatively low expression during the first five time points followed by obvious upregulation at $21 \mathrm{dpi}$. The high expression abundance of this effector, specifically at $21 \mathrm{dpi}$, suggests a role in egg laying and perhaps the reproductive success of the nematode (Fig. 4L). Consistent with this hypothesized function, the mRNA of this candidate effector was specifically localized to the rectal glands of the adult female nematodes. This was intriguing because the rectal glands produce a gelatinous matrix that surrounds the nematode's egg mass (Maggenti and Allen 1960). In addition to enhancing the viability of the eggs in the soil, the gelatinous matrix is implicated in forming a pore in the surrounding plant tissue that allows the egg mass to escape the root (Orion and Franck 1990; Orion et al. 2001). These observations indicate that proteins secreted in the gelatinous matrix could be involved in egg laying and, perhaps, the reproductive success of the parasite. Interestingly, another very recent study by Danchin and associates (2013) also identified Minc00801 as an "effector-like" candidate. These authors showed that silencing of its transcript using small interfering RNA resulted in a significant reduction in the number of $M$. incognita-induced galls. Taken together, these results indicate that Minc00801 is a protein that supports $M$. incognita's ability to infect, and should be investigated further.

In conclusion, this latest effort of nematode gland transcriptomics coupled with the use of next-generation 454 sequencing technology has allowed us to explore the gland cells of $M$. incognita on an unprecedented level. The novel effector proteins identified in this study have significantly expanded the effector repertoire of $M$. incognita and set the stage for a more complete understanding of how this parasite infects its host plants.

\section{MATERIALS AND METHODS}

Microaspiration of gland cell region and mRNA extraction.

M. incognita was grown on greenhouse tomato roots (Lycopersicon esculentum 'Marion'). Parasitic-stage nematodes (J2 to J4) were extracted from roots, surface sterilized, and imbedded in $0.7 \%$ agarose. A glass micropipette containing $10 \mu \mathrm{l}$ of mRNA extraction buffer was used to aspirate the gland cell cytoplasm from individual nematodes. In total, two pools of gland cell cytoplasm, each derived from 50 individual nematodes, were collected and stored at $-80^{\circ} \mathrm{C}$ until mRNA extraction, as previously described (Huang et al. 2003). Poly(A) RNA was extracted separately from both aspirated cytoplasm pools using Dynabeads Oligo $(\mathrm{dT})_{25}$ magnetic beads (Dynal, Lake Success, NY, U.S.A), and eluted with diethylpyrocarbonate (DEPC)-treated double-distilled $\mathrm{H}_{2} \mathrm{O}$, as previously described (Gao et al. 2001). First-strand cDNA synthesis was then performed on $4 \mu \mathrm{l}$ of the pooled mRNA sample in a $10-\mu \mathrm{l}$ reaction, which also included $0.5 \mu 1$ of 3 -rapid amplification of cDNA ends cDNA Synthesis Primer (10 mM; Clontech Laboratories, Palo Alto, CA, U.S.A.), $0.5 \mu$ of SMART II oligonucleotide $(10 \mu \mathrm{M}$; Clontech Laboratories), $2.0 \mu \mathrm{l}$ of $5 \times$ first-strand buffer, $1.0 \mu \mathrm{l}$ of dithiothreitol $(20 \mathrm{mM}), 1.0 \mu \mathrm{l}$ of dNTP $(10 \mathrm{mM})$, and $1.0 \mu \mathrm{l}$ of Superscript II $(200 \mathrm{U} / \mu \mathrm{l}$; GIBCO-BRL, Grand Island, NY, U.S.A). The SMART oligonucleotide system was used to enrich for full-length cDNA. The reactions were incubated for $1.5 \mathrm{~h}$ at $42^{\circ} \mathrm{C}$, after which 90 $\mu l$ of Tris-EDTA buffer $(10 \mathrm{mM}$ Tris [pH 7.6] and $1 \mathrm{mM}$ EDTA) was added. ligation-dependent-PCR was then performed using a $100-\mu \mathrm{l}$ reaction containing first-strand reaction solution $(10 \mu \mathrm{l}), 2 \mu \mathrm{l}$ of $\mathrm{dNTP}(10 \mathrm{mM}), 10 \mu \mathrm{l}$ of TaqPlus Long low-salt buffer, $1 \mu$ of TaqPlus Long polymerase (Stratagene, La Jolla, CA, U.S.A.), and $2 \mu$ of Nested Universal Primer (Clontech Laboratories). PCR was performed with a hot start followed by 24 cycles of $94^{\circ} \mathrm{C}(20 \mathrm{~s}), 65^{\circ} \mathrm{C}(30 \mathrm{~s})$, and $72^{\circ} \mathrm{C}$ (6 min). Negative controls using DEPC water were performed at each reaction step above.

\section{Sequencing and assembly.}

The gland-cell-derived cDNA library was split into two separate pools, one of which was nebulized to reduce the fragment size, and both were sequenced together using the Roche 454 platform (University of Iowa, Iowa City). Sequencing produced 1.7 million total reads with an average length of $281 \mathrm{bp}$. After removing short and low-complexity reads (SeqClean), 623,000 reads were assembled using Newbler v2.5.

\section{Sequence analysis and identification of candidate effectors.}

Isotigs were translated (Prot4EST V3.0b), and the protein predictions were then blasted against all the known proteins from both $M$. incognita and $M$. hapla genomes using a cut off of $95 \%$ ID over $75 \%$ of the length of the Isotig. After the known proteins were identified, they were analyzed using the OrthoMCL algorithm which, in brief, uses an all-against-all blast strategy to sort proteins from different organisms into groups of likely orthologs and paralogs (Chen et al. 2006). By grouping the identified root-knot nematode proteins with the total known proteins from 18 other selected species (five freeliving nematode species, five parasitic nematodes, five parasitic Helminths, the fly, and two host plant species), proteins which had orthologs in free-living nematode species were excluded, while those that grouped exclusively with proteins from parasites or host plant species were selected as candidates. As an added measure, the effector candidates were then compared using BLAST research against free-living nematodes to assure the absence of consequential homology (over 35 bits). The remaining candidates were analyzed for the presence of an $\mathrm{N}$-terminal signal peptide as well as the absence of a trans-membrane domain outside of the first 60 amino acids of the $\mathrm{N}$ terminus (Phobius) (Kall et al. 2004). This first list of previously annotated secreted candidates consisted of 91 fulllength proteins. 
In situ hybridization of effector transcripts.

Specific forward and reverse primers were designed for the coding sequence of each of the 91 candidate genes. These primers were used to amplify an amplicon of 150 to $300 \mathrm{bp}$ in length from cDNA pools generated from $M$. incognita. This amplicon was used as a template in a unidirectional PCR to produce single-stranded sense and antisense DIG-labeled probes for each candidate effector transcript. Unidirectional PCRs were performed in $25-\mu 1$ volumes using a DIG-nucleotide labeling kit (Roche, Indianapolis, IN, U.S.A.). In situ hybridizations were performed on mixed parasitic stages of M. incognita, as previously described (de Boer et al. 1998). Established parasitic populations of nematodes were extracted from the roots of tomato (L. esculentum 'Rutgers') by maceration of the infected tissue followed by progressive sieving, as previously described (de Boer et al. 1999). These parasitic stages were supplemented with freshly hatched preparasitic $M$. incognita J2s. Mixed-stage nematodes were fixed in a $2 \%$ formaldehyde solution. Fixed nematodes were permeabilized by hand cutting with a razorblade on a glass slide in combination with a partial proteinase- $\mathrm{K}$ digestion $(20 \mathrm{mg} / \mathrm{ml}, 30 \mathrm{~min}$ at room temperature). DIG-labeled probes were hybridized to permeabilized tissues overnight at $50^{\circ} \mathrm{C}$. Hybridized probes within the nematode were detected using anti-DIG antibody conjugated to alkaline phosphatase and its substrate. Samples were then visualized using a Zeiss Axiovert 100 inverted light microscope.

\section{Developmental expression patterns of putative effectors.}

To assess the developmental expression profile of our positive candidates, we designed specific qRT-PCR primers for 12 unique transcripts ( 1 representative from each paralogous gene family). Four biological replicates of $M$. incognita were separately extracted at each of the five time points during parasitism (eggs and preparasitic J2s at 3, 7, 14, and 21 dpi. Total RNA was extracted from each sample using the Perfect Pure RNA fibrous tissue extraction kit (5prime), according to the manufacturer's instructions. For qRT-PCR, approximately $2 \mathrm{ng}$ of $M$. incognita mRNA was used for cDNA synthesis and PCR amplification in 15- $\mu$ l reactions using a one-step RT-PCR kit (Quanta Biosciences, Gaithersburg, MD, U.S.A.), according to the manufacturer's protocol. qRT-PCR were run using an iCycler RT-PCR thermal cycler (Bio-Rad, Hercules, CA, U.S.A.) and the following program: $50^{\circ} \mathrm{C}$ for $10 \mathrm{~min}, 95^{\circ} \mathrm{C}$ for $5 \mathrm{~min}$, and 40 cycles of $95^{\circ} \mathrm{C}$ for $30 \mathrm{~s}$ and $60^{\circ} \mathrm{C}$ for $30 \mathrm{~s}$. Four replicated reactions were run for each primer pair for each mRNA sample. qRT-PCR data were analyzed using the iCycler IQ Optical Systems Software (version 3.0a; Bio-Rad). After PCR amplification, the reactions were subjected to a temperature ramp to generate the dissociation curves to assure specific amplification products. $M$. incognita actin and tubulin primer pairs were used as internal controls to normalize gene expression levels at each time point. Following the $2^{-\Delta \Delta \mathrm{C}}$ method (Livak and Schmittgen 2001), relative fold-change values were calculated using gene expression levels in the egg as a base line. $P$ values for each time point were calculated using Bonferroni pairwise comparisons. A significant difference $(P$ value $<0.05)$ was considered statistically significant only if it was consistently seen in both the actin and tubulin normalizations.

\section{Subcellular localization.}

Full-length coding sequences of 11 putative effector genes were amplified from $M$. incognita cDNA (1 representative from each paralogous gene family from the esophageal gland cells), and cloned into the pGEM-T Easy vector (Promega Corp., Madison, WI, U.S.A.) for sequencing. Confirmed clones were used as templates in PCRs to amplify fragments without the signal peptide region along with appropriate restriction sites for cloning into the pSAT6-eYFP vectors, obtained from ARBC. Cloning into the pSAT6-eYFP vectors created YFP fusion proteins under the control of the CaMV 35S promoter, which were confirmed by sequencing. Confirmed vectors were bombarded into onion epidermal cells via biolistic bombardment, as previously described (Elling et al. 2007). Bombarded onion cells were incubated for 16 to $24 \mathrm{~h}$ in the dark, then visualized using a Zeiss Axiovert 100 inverted light microscope.

\section{LITERATURE CITED}

Abad, P., and Williamson, V. M. 2010. Plant-nematode interaction: A sophisticated dialogue. Adv. Bot. Res. 53:147-192.

Abad, P., Gouzy, J., Aury, J. M., Castagnone-Sereno, P., Danchin, E. G. J., Deleury, E., Perfus-Barbeoch, L., Anthouard, V., Artiguenave, F., Blok, V. C., Caillaud, M.-C., Coutinho, P. M., Dasilva, C., De Luca, F., Deau, F., Esquibet, M., Flutre, T., Goldstone, J. V., Hamamouch, N., Hewezi, T., Jaillon, O., Jubin, C., Leonetti, P., Magliano1, M., Maier, T. R., Markov, G. V., McVeigh, P., Pesole, G., Poulain, J., Robinson-Rechavi, M., Sallet, E., Ségurens, B., Steinbach, D., Tytgat, T., Ugarte, E., van Ghelder, C., Veronico, P., Baum, T. J., Blaxter, M., Bleve-Zacheo, T., Davis, E. L., Ewbank, J. J., Favery, B., Grenier, E., Henrissat, B., Jones, J. T., Laudet, V., Maule, A. G., Quesneville, H., Rosso, M.-N., Schiex, T., Smant, G., Weissenbach, J., and Wincker, P. 2008. Genome sequence of the metazoan plant-parasitic nematode Meloidogyne incognita. Nat. Biotechnol. 26:909-915.

Abubucker, S., Martin, J., Taylor, C. M., and Mitreva, M. 2011. HelmCoP: An online resource for helminth functional genomics and drug and vaccine targets prioritization. PLoS One 6:e21832. Published online.

Bekal, S., Niblack, T. L., and Lambert, K. N. 2003. A chorismate mutase from the soybean cyst nematode Heterodera glycines shows polymorphisms that correlate with virulence. Mol. Plant-Microbe Interact. 16:439-446.

Bellafiore, S., Shen, Z. X., Rosso, M. N., Abad, P., Shih, P., and Briggs, S.P. 2008. Direct identification of the Meloidogyne incognita secretome reveals proteins with host cell reprogramming potential. PLoS Pathog. 4:e1000192. Published online.

Bird, D. M., Williamson, V. M., Abad, P., McCarter, J., Danchin, E. G. J., Castagnone-Sereno, P., and Opperman, C. H. 2009. The genomes of root-knot nematodes. Annu. Rev. Phytopathol. 47:333-351.

Brandt, S. P. 2005. Microgenomics: Gene expression analysis at the tissuespecific and single-cell levels. J. Exp. Bot. 56:495-505.

Castagnone-Sereno, P., Semblat, J. P., and Castagnone, C. 2009. Modular architecture and evolution of the map-1 gene family in the root-knot nematode Meloidogyne incognita. Mol. Genet. Genomics 282:547-554.

Chemello, F., Bean, C., Cancellara, P., Laveder, P., Reggiani, C., and Lanfranchi, G. 2011. Microgenomic analysis in skeletal muscle: Expression signatures of individual fast and slow myofibers. PLoS One 6:e16807. Published online.

Chen, F., Mackey, A. J., Stoeckert, C. J., and Roos, D. S. 2006. OrthoMCLDB: Querying a comprehensive multi-species collection of ortholog groups. Nucleic Acids Res. 34:D363-D368.

Danchin, E. G., Arguel, M. J., Campan-Fournier, A., Perfus-Barbeoch, L., Magliano, M., Rosso, M. N., Da Rocha, M., Da Silva, C., Nottet, N., Labadie, K., Guy, J., Artiguenave, F., and Abad, P. 2013. Identification of novel target genes for safer and more specific control of root-knot nematodes from a pan-genome mining. PLoS Pathog. 9:e1003745. Published online.

Daniel, J., Coulter, J., Woo, J. H., Wilsbach, K., and Gabrielson, E. 2011. High levels of the Mps1 checkpoint protein are protective of aneuploidy in breast cancer cells. Proc. Natl. Acad. Sci. U.S.A. 108:5384-5389.

de Boer, J. M., Yan, Y., Smant, G., Davis, E. L., and Baum, T. J. 1998. Insitu hybridization to messenger RNA in Heterodera glycines. J. Nematol. 30:309-312.

de Boer, J. M., Yan, Y., Wang, X., Smant, G., Hussey, R. S., Davis, E. L., and Baum, T. J. 1999. Developmental expression of secretory beta-1,4endoglucanases in the subventral esophageal glands of Heterodera glycines. Mol. Plant-Microbe Interact. 12:663-669.

de Oliveira, E. A., Romeiro, N. C., Ribeiro Eda, S., Santa-Catarina, C., Oliveira, A. E., Silveira, V., de Souza Filho, G. A., Venancio, T. M., and Cruz, M. A. 2012. Structural and functional characterization of the protein kinase Mps1 in Arabidopsis thaliana. PLoS One 7:e45707. Published online.

Doyle, E. A., and Lambert, K. N. 2003. Meloidogyne javanica chorismate mutase 1 alters plant cell development. Mol. Plant-Microbe Interact. 16:123-131. 
Elling, A. A., Davis, E. L., Hussey, R. S., and Baum, T. J. 2007. Active uptake of cyst nematode parasitism proteins into the plant cell nucleus. Int. J. Parasitol. 37:1269-1279.

Gao, B. L., Allen, R., Maier, T., Davis, E. L., Baum, T. J., and Hussey, R. S. 2001. Identification of putative parasitism genes expressed in the esophageal gland cells of the soybean cyst nematode Heterodera glycines. Mol. Plant-Microbe Interact. 14:1247-1254.

Haas, B. J., Kamoun, S., Zody, M. C., Jiang, R. H. Y., Handsaker, R. E., Cano, L. M., Grabherr, M., Kodira, C. D., Raffaele, S., Torto-Alalibo, T., Bozkurt, T. O., Ah-Fong, A. M. V., Alvarado, L., Anderson, V. L., Armstrong, M. R., Avrova, A., Baxter, L., Beynon, J., Boevink, P. C. Bollmann, S. R., Bos, J. I. B., Bulone, V., Cai, G., Cakir, C., Carrington, J. C., Chawner, M., Conti, L., Costanzo, S., Ewan, R., Fahlgren, N., Fischbach, M. A., Fugelstad, J., Gilroy, E. M., Gnerre, S., Green, P. J., Grenville-Briggs, L. J., Griffith, J., Grünwald, N. J., Horn, K., Horner, N. R., Hu, C.-H., Huitema, E., Jeong, D.-H., Jones, A. M. E., Jones, J. D. G., Jones, R. W., Karlsson, E. K., Kunjeti, S. G., Lamour, K., Liu, Z., Ma, L., MacLean, D., Chibucos, M. C., McDonald, H., McWalters, J., Meijer, H. J. G., Morgan, W., Morris, P. F., Munro, C. A., O'Neill1, K., Ospina-Giraldo, M., Pinzón, A., Pritchard, L., Ramsahoye, B., Ren, Q., Restrepo, S., Roy, S., Sadanandom, A., Savidor, A., Schornack, S., Schwartz, D. C., Schumann, U. D., Schwessinger, B., Seyer, L., Sharpe, T., Silvar, C., Song, J., Studholme, D. J., Sykes, S., Thines, M., van de Vondervoort, P. J. I., Phuntumart, V., Wawra, S., Weide, R., Win, J., Young, C., Zhou, S., Fry, W., Meyers, B. C., van West, P., Ristaino, J., Govers, F., Birch, P. R. J., Whisson, S. C. W., Judelson, H. S., and Nusbaum, C. 2009. Genome sequence and analysis of the Irish potato famine pathogen Phytophthora infestans. Nature 461:393-398.

Hewezi, T., and Baum, T. 2013. Manipulation of plant cells by cyst and root-knot nematode effectors. Mol. Plant-Microbe Interact.. 26:9-16.

Hewezi, T., Howe, P., Maier, T. R., Hussey, R. S., Mitchum, M. G., Davis, E. L., and Baum, T. J. 2008. Cellulose binding protein from the parasitic nematode Heterodera schachtii interacts with Arabidopsis pectin methylesterase: Cooperative cell wall modification during parasitism. Plant Cell 20:3080-3093.

Huang, C. S. 1985. Formation, anatomy and physiology of giant cells induced by root-knot nematodes. An advanced treatise on Meloidogyne. Biology Control 1:155-164.

Huang, G. Z., Gao, B. L., Maier, T., Allen, R., Davis, E. L., Baum, T. J., and Hussey, R. S. 2003. A profile of putative parasitism genes expressed in the esophageal gland cells of the root-knot nematode Meloidogyne incognita. Mol. Plant-Microbe Interact. 16:376-381.

Huang, G. Z., Dong, R. H., Allen, R., Davis, E. L., Baum, T. J., and Hussey, R. S. 2006. A root-knot nematode secretory peptide functions as a ligand for a plant transcription factor. Mol. Plant-Microbe Interact. 19:463-470

Jaouannet, M., Magliano, M., Arguel, M. J., Gourgues, M., Evangelisti, E., Abad, P., and Rosso, M. N. 2013. The root-knot nematode calreticulin Mi-CRT is a key effector in plant defense suppression. Mol. PlantMicrobe Interact. 26:97-105.

Jaubert, S., Milac, A. L., Petrescu, A. J., de Almeida-Engler, J., Abad, P., and Rosso, M. N. 2005. In planta secretion of a calreticulin by migratory and sedentary stages of root-knot nematode. Mol. Plant-Microbe Interact. 18:1277-1284.

Jones, M. G., and Payne, H. L. 1978. Early stages of nematode-induced giant-cell formation in roots of Impatiens balsamina. J. Nematol. 10:70-84.

Kall, L., Krogh, A., and Sonnhammer, E. L. 2004. A combined transmembrane topology and signal peptide prediction method. J. Mol. Biol. 338:1027-1036.

Koenning, S. R., Overstreet, C., Noling, J. W., Donald, P. A., Becker, J. O., and Fortnum, B. A. 1999. Survey of crop losses in response to phytoparasitic nematodes in the United States for 1994. J. Nematol. 31:587618.

Lin, B., Zhuo, K., Wu, P., Cui, R., Zhang, L. H., and Liao, J. 2012. A novel effector protein MJ-NULG1a targeted to giant cell nuclei plays a role in Meloidogyne javanica parasitism. Mol. Plant-Microbe Interact. 1:55-66.
Liu, X., and Winey, M. 2012. The MPS1 family of protein kinases. Annu. Rev. Biochem. 81:561-585.

Livak, K. J., and Schmittgen, T. D. 2001. Analysis of relative gene expression data using real-time quantitative PCR and the 2(-delta delta $\mathrm{C}(\mathrm{T})$ ) method. Methods 25:402-408.

Maggenti, A. R., and Allen, M. W. 1960. The origin of the gelatinous matrix in Meloidogyne. Proc. Helminthol. Soc. Wash. 27:4-10.

Mitchum, M. G., Hussey, R. S., Baum, T. J., Wang, X., Elling, A. A., Wubben, M., and Davis, E. L. 2013. Nematode effector proteins: An emerging paradigm of parasitism. New Phytol. 4:879-894.

Opperman, C. H., Bird, D. M., Williamson, V. M., Rokhsar, D. S., Burke, M., Cohn, J., Cromer, J., Diener, S., Gajan, J., Graham, S., Houfek, T. D., Liu, Q., Mitros, T., Schaff, J., Schaffer, R., Scholl, E., Sosinski, B. R., Thomas, V. P., and Windham, E. 2008. Sequence and genetic map of Meloidogyne hapla: A compact nematode genome for plant parasitism. Proc. Natl. Acad. Sci. U.S.A. 105:14802-14807.

Orion, D., and Franck, A. 1990. An electron microscopy study of cell wall lysis by Meloidogyne javanica gelatinous matrix. Rev. Nematol. 13:105-108.

Orion, D., Kritzman, G., Meyer, S. L., Erbe, E. F., and Chitwood, D. J. 2001. A role of the gelatinous matrix in the resistance of root-knot nematode (Meloidogyne spp.) eggs to microorganisms. J. Nematol. 33:203-207.

Poueymiro, M., and Genin, S. 2009. Secreted proteins from Ralstonia solanacearum: A hundred tricks to kill a plant. Curr. Opin. Microbiol. 12:44-52.

Quevillon, E., Silventoinen, V., Pillai, S., Harte, N., Mulder, N., Apweiler, R., and Lopez, R. 2005. InterProScan: Protein domains identifier. Nucleic Acids Res. 33:W116-120.

Raffaele, S., Farrer, R. A., Cano, L. M., Studholme, D. J., MacLean, D., Thines, M., Jiang, R. H. Y., Zody, M. C., Kunjeti, S. G., Donofrio, N. M., Meyers, B. C., Nusbaum, C., and Kamoun, S. 2010. Genome evolution following host jumps in the Irish potato famine pathogen lineage. Science 330:1540-1543.

Roze, E., Hanse, B., Mitreva, M., Vanholme, B., Bakker, J., and Smant, G. 2008. Mining the secretome of the root-knot nematode Meloidogyne chitwoodi for candidate parasitism genes. Mol. Plant Pathol. 9:1-10.

Sasser, J. N., and Freckman, D. W. 1986. A world perspective on nematology-the role of the society. J. Nematol. 18:596-596.

Schirawski, J., Mannhaupt, G., Munch, K., Brefort, T., Schipper, K., Doehlemann, G., Di Stasio, M., Rossel, N., Mendoza-Mendoza, A., Pester, D., Müller, O., Winterberg, B., Meyer, E., Ghareeb, H., Wollenberg, T., Münsterkötter, M., Wong, P., Walter, M., Stukenbrock, E., Güldener, U., and Kahmann, R. 2010. Pathogenicity determinants in smut fungi revealed by genome comparison. Science 330:1546-1548.

Semblat, J. P., Rosso, M. N., Hussey, R. S., Abad, P., and CastagnoneSereno, P. 2001. Molecular cloning of a cDNA encoding an amphidsecreted putative avirulence protein from the root-knot nematode Meloidogyne incognita. Mol. Plant-Microbe Interact. 14:72-79.

Tomalova, I., Iachia, C., Mulet, K., and Castagnone-Sereno, P. 2012. The MAP-1 gene family in root-knot nematodes, Meloidogyne spp.: A set of taxonomically restricted genes specific to clonal species. PLoS One 7:e38656. Published online.

Tytgat, T., Vanholme, B., De Meutter, J., Claeys, M., Couvreur, M., Vanhoutte, I., Gheysen, G., Van Criekinge, W., Borgonie, G., and Coomans, A. 2004. A new class of ubiquitin extension proteins secreted by the dorsal pharyngeal gland in plant parasitic cyst nematodes. Mol. Plant-Microbe Interact. 17:846-852.

Vieira, P., Danchin, E. G., Neveu, C., Crozat, C., Jaubert, S., Hussey, R. S., Engler, G., Abad, P., de Almeida-Engler, J., Castagnone-Sereno, P., and Rosso, M. N. 2011. The plant apoplasm is an important recipient compartment for nematode secreted proteins. J. Exp. Bot. 62:1241-1253.

Yu, N. Y., Wagner, J. R., Laird, M. R., Melli, G., Rey, S., Lo, R., Dao, P., Sahinalp, S. C., Ester, M., Foster, L. J., and Brinkman, F. S. 2010 PSORTb 3.0: Improved protein subcellular localization prediction with refined localization subcategories and predictive capabilities for all prokaryotes. Bioinformatics 26:1608-1615. 